of phenylketonuria should be given a trial with L-dopa.

\section{References}

1 Farquhar JW, Richmond J, Tait HP. Phenylketonuria in pediatric practice. Clin Pediatr (Phila) 1963; 2: 504-16.

2 Payne RS. The variability in manifestations of untreated patients with phenylketonuria (phenylpyruvic aciduria). Pediatrics 1957; 20: 290-302.

3 Anonymous. The duration of treatment of phenylketonuria. Lancet 1974; i : 971-2.
4 Curtius H-cH, Baerlocher K, Völlmin JA. Pathogenesis of phenylketonuria: inhibition of dopa and catecholamine synthesis in patients with phenylketonuria. Clin Chim Acta 1972; 42: 235-9.

Correspondence to Dr Michael MacLeod, Medical Unit, Eastern General Hospital, Seafield Street, Edinburgh EH6 7LN.

Received 11 January 1983

\title{
Effects of artificial surfactant on lung function and blood gases in idiopathic respiratory distress syndrome
}

\author{
A D MILNER, H VYAS, AND I E HOPKIN \\ Department of Child Health, City Hospital, Nottingham
}

SUMMARY We have investigated the effect of giving two $25 \mathrm{mg}$ doses of dry surfactant powder to the airways of 10 preterm babies with severe idiopathic respiratory distress syndrome requiring intermittent positive pressure ventilation. No useful change in static total compliance or blood gases was seen. We conclude that dry surfactant powder does not have a role in the management of severe idiopathic respiratory distress syndrome.

Recent studies from $\mathrm{Japan}^{1}$ and Canada ${ }^{2}$ suggested that giving artificial surfactant may improve rapidly and dramatically the clinical condition of babies with severe idiopathic respiratory distress syndrome (IRDS) requiring ventilatory support. These were, however, anecdotal investigations, and the only well controlled trial reported so far failed to show that the treatment altered blood gas values or clinical state to any appreciable extent. ${ }^{3}$ For this reason we have completed a trial examining the effects of artificial surfactant, delivered to the respiratory tract as a dry powder on static compliance and transcutaneous oxygen and carbon dioxide in preterm babies with severe IRDS.

\section{Method}

Ten preterm babies with a mean gestational age of 30.1 weeks (range 27-33 weeks) and a mean birthweight of $1.45 \mathrm{~kg}$ (range $0.77-1.86 \mathrm{~kg}$ ) were investigated. All had a clinical diagnosis of IRDS with typical chest $x$-ray findings and a negative shake test on admission to the neonatal unit. Their mean age at the time of study was $17 \cdot 3$ hours (range 6-29 hours) and they had all required ventilation for at least 5 hours. Six were born by normal spontaneous vertex delivery and 4 by caesarean section. Their ventilator settings were mean inflation pressures $23 \cdot 1 / 0 \mathrm{~cm} \mathrm{H}_{2} \mathrm{O}$, (range $15-35 / 0 \mathrm{~cm} \mathrm{H}_{2} \mathrm{O}$ ) at a rate of 42.4 (range 24-60 per minute); an inspiratory: expiratory ratio of $1: 1$ (range $0 \cdot 7-1: 1-1.5$ ); and an inspired oxygen of $71.5 \%$ (range $50-100 \%$ ). These settings were left unchanged throughout the study.

Inflation pressure was measured using a strain gauge pressure transducer connected to the endotracheal tube by a 21 gauge butterfly needle. This was calibrated against a water column at the end of each investigation. Changes in thoracic volume were recorded using an inflated rubber jacket which encompassed the chest and abdomen and was then inflated to a pressure of $2 \mathrm{~cm} \mathrm{H}_{2} \mathrm{O}$. Tidal exchange produced pressure swings in the jacket of less than $1 \mathrm{~mm} \mathrm{H}_{2} \mathrm{O}$. Calibration was achieved by injecting and withdrawing $20 \mathrm{ml}$ aliquots of air into and out of the jacket at intervals of 4 to 5 breaths and measuring the change in end-tidal baseline. ${ }^{4}$ All signals were collected on an FM tape recorder (Racal) and subsequently relayed onto ultraviolet sensitive paper for analysis. Transcutaneous carbon dioxide and usually transcutaneous oxygen were monitored throughout using the Radiometer transcutaneous blood gas system with the 2 probes attached to the abdominal skin under the jacket. In 3 babies arterial oxygen was monitored throughout using the Searle intra-arterial oxygen electrode and the transcutaneous oxygen measurements were then omitted.

Once the jacket, probes, and transducers were in position measurements of transcutaneous oxygen 
and carbon dioxide were recorded at 2 minute intervals for 20 minutes to ensure that the baby's condition was stable. At the end of this period static compliance was obtained by switching the ventilator (Draeger Babylog) to manual mode and ventilating the baby at rates $>100$ per minute for 30 seconds to reduce the respiratory drive. We then maintained the inflation pressure for 2-3 seconds before releasing the pressure for a further 2-3 seconds. Static compliance was calculated by dividing the fall in volume as the pressure was released, by the simultaneous fall in inflation pressure. ${ }^{5}$ At least 4 measurements were obtained on each occasicn. The baby was then returned to standard ventilator settings for 2-3 minutes. At the end of this period the baby was disconnected from the ventilator manifold and the endotracheal tube was attached to the nozzle of a standard sodium cromoglycate nasal insufflator, which is supplied with a rubber inflation bulb. The bulb was squeezed 6 times at approximately 1 second intervals. This produced transient inflation pressures of between 40 and $60 \mathrm{~cm}$ of water pressure and volume changes slightly in excess of those occurring when the baby was attached to the ventilator. The baby was then reconnected to the ventilator and transcutaneous oxygen and carbon dioxide measurements continued at 2 minute intervals for a further 20 minutes.

The static compliance measurement and insufflation were then repeated in the same way, except that this time the sodium cromoglycate insufflator was loaded with a capsule containing $25 \mathrm{mg}$ of artificial surfactant $(70 \%$ dipalmitoylphosphatidylcholine and $30 \%$ unsaturated phosphatidylglycerol). The total procedure was repeated giving the placebo and active treatment 20 and 40 minutes later, respectively. Finally, after a further 20 minute interval, the insufflation was omitted and instead a volume of saline, equivalent to the baby's dead space $(2.2 \mathrm{ml} / \mathrm{kg}$ bodyweight), was injected down the endotracheal tube and the ventilator reconnected. Static compliance measurements were repeated 20 minutes later. Arterial blood gas samples taken 12 hours after the end of the investigation were compared with values obtained before the study began. This project was approved by the North Nottingham Health District Ethical Committee.

\section{Results}

The first total static compliance measurements ranged from $0.17-0.82$ (mean 0.37 ) $\mathrm{ml} / \mathrm{cm}_{2} \mathrm{O}$. Throughout the period of assessment there was a slight deterioration in compliance, with some individual variation (Figure). No baby showed dramatic improvement in compliance in the 20 minute period after surfactant had been given. The transcutaneous carbon dioxide and the arterial oxygen values showed transient mild deterioration during the measurement of static compliance, but again no improvement could be seen as a result of surfactant treatment (Table). Arterial blood gas values 12 hours after the investigations were essentially unchanged from the values immediately before investigation. After 12 hours inspired oxygen was unchanged at $71 \%$, the mean inspiratory: expiratory ratio was still $1: 1$, but the rate had fallen

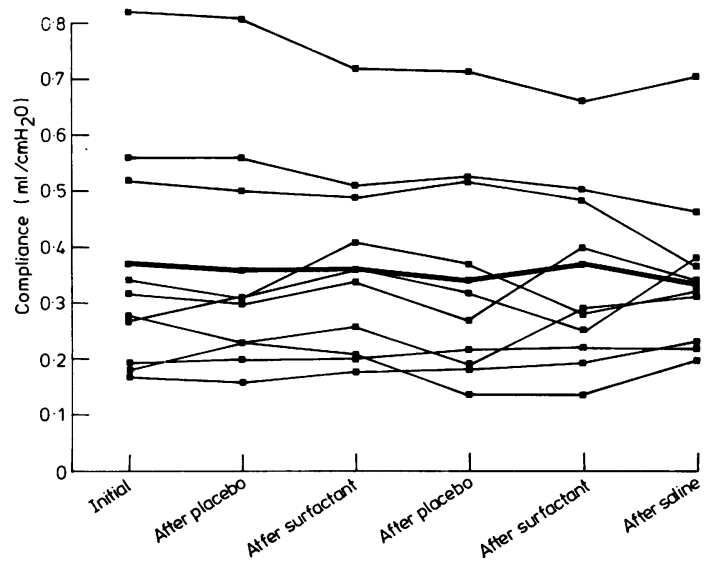

Figure Total static compliance measurements initially, and 20 minutes after each insufflation. Individual and mean results (bold line) are shown.

Table Arterial/transcutaneous oxygen $\left(\mathrm{PaO}_{2}\right)$ and carbon dioxide levels $\left(\mathrm{PaCO}_{2}\right)$ before, during, and 12 hours after the surfactant study

\begin{tabular}{|c|c|c|c|c|c|c|c|c|}
\hline & $\begin{array}{l}\text { Before } \\
\text { study* }\end{array}$ & Initial & $\begin{array}{l}\text { After first } \\
\text { placebo }\end{array}$ & $\begin{array}{l}\text { After first } \\
\text { surfactant }\end{array}$ & $\begin{array}{l}\text { After second } \\
\text { placebo }\end{array}$ & $\begin{array}{l}\text { After second } \\
\text { surfactant }\end{array}$ & $\begin{array}{l}\text { After } \\
\text { saline }\end{array}$ & $\begin{array}{l}12 \text { hours after } \\
\text { study* }\end{array}$ \\
\hline $\begin{array}{c}\mathrm{PaO}_{2}(\mathrm{kPa}) \\
\text { Mean } \\
\text { Range }\end{array}$ & $\begin{array}{l}7 \cdot 0 \\
3 \cdot 4-9 \cdot 3\end{array}$ & $\begin{array}{l}6 \cdot 2 \\
4 \cdot 5-7 \cdot 5\end{array}$ & $\begin{array}{l}6 \cdot 7 \\
3 \cdot 5-8 \cdot 8\end{array}$ & $\begin{array}{l}7 \cdot 3 \\
4 \cdot 3-10 \cdot 0\end{array}$ & $\begin{array}{l}6 \cdot 9 \\
2 \cdot 0-11 \cdot 5\end{array}$ & $\begin{array}{l}6 \cdot 6 \\
4 \cdot 3-9 \cdot 5\end{array}$ & $\begin{array}{l}7 \cdot 1 \\
4 \cdot 0-8 \cdot 9\end{array}$ & $\begin{array}{l}7 \cdot 2 \\
5 \cdot 4-9 \cdot 1\end{array}$ \\
\hline $\begin{array}{c}\mathrm{PaCO}_{2}(\mathrm{kPa}) \\
\text { Mean } \\
\text { Range }\end{array}$ & $\begin{array}{l}6 \cdot 2 \\
4 \cdot 0-9 \cdot 1\end{array}$ & $\begin{array}{l}10 \cdot 7 \\
6 \cdot 4-12.9\end{array}$ & $\begin{array}{l}10 \cdot 1 \\
6 \cdot 0-13 \cdot 6\end{array}$ & $\begin{array}{l}10 \cdot 4 \\
5 \cdot 9-14 \cdot 0\end{array}$ & $\begin{array}{l}11 \cdot 0 \\
6 \cdot 3-15 \cdot 7\end{array}$ & $\begin{array}{l}10 \cdot 6 \\
5 \cdot 2-16 \cdot 4\end{array}$ & $\begin{array}{l}11 \cdot 2 \\
6 \cdot 5-13 \cdot 5\end{array}$ & $\begin{array}{l}6 \cdot 3 \\
4 \cdot 6-10 \cdot 1\end{array}$ \\
\hline
\end{tabular}

*Arterial blood gas samples.

Conversion: SI to traditional units $-\mathrm{PaO}_{2}$ and $\mathrm{PaCO}_{2}$ : $1 \mathrm{kPa} \approx 0.133 \mathrm{mmHg}$. 
by 4 per minute to 38 and the inflation pressure by 1.4 to $20 \mathrm{~cm} \mathrm{H}_{2} \mathrm{O}$. None of these changes was statistically significant, suggesting that the babies had neither improved nor deteriorated.

\section{Discussion}

In this study we have been unable to show any improvement in lung mechanics or transcutaneous blood gas measurements after 2 doses of artificial surfactant were delivered to the airways of preterm babies requiring intermittent positive pressure ventilation for IRDS. Blood gas values 12 hours after the study did not indicate that a delayed response was occurring. These findings are at variance with those of Fujiwara et al., ${ }^{2}$ but similar to those of Wilkinson et al..$^{3}$ There are several possible reasons for this. Firstly, our surfactant may have been inactive. This is unlikely, as many in vitro studies have shown this particular preparation to be highly active ${ }^{6}$; but there are some who claim that artificial surfactants are not as active as natural surfactant. ${ }^{7}$ Secondly, the surfactant may not have penetrated far enough into the lungs to achieve a monomolecular layer where required. This too is unlikely as insufflation of the powder certainly deposited surfactant down into the large airways. As the wet surface of the large airways is in direct continuity with the alveoli, any lowering of the surface tension locally would cause the surfactant to spread in the same way that a drop of washing up liquid immediately spreads across the surface of the water. The final insufflation of saline would help to deliver any surfactant deposited in the endotracheal tube, but this too was ineffective. Finally, the dose may have been too small: but $50 \mathrm{mg}$ is a very large dose compared with that required to establish a monomolecular layer throughout the lungs.

We suspect that the improvement seen by the Japanese and Canadian workers may be related to the way the surfactant was given, which included a period of hyperventilation with an anaesthetic rebreathing bag and also instillation of volumes of saline into the lungs-equivalent to as much as $500 \mathrm{ml}$ in the adult. This combination may be useful for the management of conditions in which hyaline membranes have formed in the lungs. We conclude that dry surfactant powder is unlikely to have a useful clinical role in the management of severe IRDS. We consider that other delivery techniques and natural surfactant still need to be explored, but think it unlikely that surfactant deficiency is the main reason for the development of IRDS in the preterm baby and that animal models are not appropriate in this disease.

We thank Dr Colin Morley, New Addenbrooke's Hospital, Cambridge, who provided us with the surfactant powder. This work was funded by a grant from the MRC.

\section{References}

1 Fujiwara T, Maeta $\mathrm{H}$, Chida S, Morita T, Watabe Y, Abe T. Artificial surfactant therapy in hyaline membrane disease. Lancet 1980; i: 55-9.

2 Smyth J A, Leroy Metcalfe I, Duffty P, et al. Surfactant therapy in hyaline membrane disease (HMD) (abstract). Pediatr Res 1981; 15: 631.

3 Wilkinson A R, Jeffrey J A, Jenkins P A. Controlled trials of dry surfactant in pre-term infants (abstract). Arch Dis Child 1982; 57: 802.

4 Helms P, Taylor B W, Milner A D, Hatch D J. Critical assessment of jacket plethysmographs for use in young children. J Appl Physiol 1982; 52: 267-73.

5 Milner A D, Hull D, Hatch D J, Cogswell J J. A new method for measuring static compliance in infants and young children. Clin Sci 1972; 43: 689-94.

6 Morley C J, Bangham A D, Johnson P, Thorburn G D, Jenkin G. Physical and physiological properties of dry line surfactant. Nature 1978; 271: 162-3.

7 Ikegami M, Jobe A, Jacobs H, Jones S J. Sequential treatments of premature lambs with an artificial surfactant and natural surfactant. $J$ Clin Invest $1981 ; 68$ : 491-6.

Correspondence to Professor A D Milner, Department of Child Health, Floor E, East Block, University Hospital, Queen's Medical Centre, Nottingham NG7 2UH.

Received 21 February 1983
SUMmARY A 10 year old girl with type 1 CriglerNajjar syndrome has been treated with daily phototherapy from birth. Her general physical and neurological development are normal.
Non-obstructive, non-haemolytic congenital hyperbilirubinaemia was described in 1952 by Crigler and Najjar. ${ }^{1}$ Arias et al. ${ }^{2}$ further clarified the syndrome and identified two main types.

Patients with type 1 have the more severe form, 